\title{
Determinants of Enrolment in Voluntary Health Insurance: Evidences from a Mixed Method Study, Kerala, India
}

\author{
Sukumar Vellakkal ${ }^{1}$ \\ ${ }^{1}$ South Asia Network for Chronic Disease (SANCD), Public Health Foundation of India (PHFI), New Delhi, India \\ Correspondence: Sukumar Vellakkal, (PhD Econ, MSc Health Econ \& Policy, MA Econ), Health Economist \& Adj. \\ Assistant Professor, South Asia Network for Chronic Disease (SANCD), Public Health Foundation of India (PHFI), \\ C-9/52, Safdarjung Development Area, New Delhi 110 016, India. Tel: 91-11-2651-3082, 91-11-2651-3099. E-mail: \\ sukumar.vellakkal@phfi.org,vellakkal@gmail.com
}

Received: September 21, 2012

Accepted: December 24, $2012 \quad$ Online Published: April 8, 2013

doi:10.5430/ijfr.v4n2p99

URL: http://dx.doi.org/10.5430/ijfr.v4n2p99

The research is financed by Indian Council for Social Science and Research (ICSSR), New Delhi, and also by a Wellcome Trust strategic award 084674/Z/08/Z.

\begin{abstract}
Background \&Objectives: Financial burden on households due to healthcare is high in India but only small segments of the population are covered with health insurance. This study has two objectives: 1 . to investigate the factors affecting enrolment in voluntary health insurance, and 2. to examine the characteristics of enrolment in terms of income-related inequality and adverse selection problem.

Data and Methods: This is a cross sectional study. Mixed method approaches- qualitative and quantitative methodswere used. In-depth interviews were conducted among officials of insurance companies, insurance consultants (insurance agents), insured and uninsured people. Subsequently, household surveys among insured and uninsured were carried to examine the significance of the determinants on enrolment.

Results: In addition to income, education and health risk, the level of awareness of people about insurance and the significant role of insurance consultants matter in the enrolment in voluntary health insurance. The enrolment in health insurance is characterised by income-related inequality in enrolment, and ii) no adverse selection.

Conclusion: We identified several demand and supply side factors negatively and positively affecting the enrolment. This study suggest that, in addition to developing a competitive insurance market with the availability of attractive health insurance products and ensuring reimbursement about eligible claims, appropriate policy measures such as promoting people's awareness on insurance and introducing better incentive structures for insurance consultants are needed to increase enrolment in health insurance.
\end{abstract}

Keywords: health insurance, enrolment, inequality, adverse selection, awareness, insurance consultant

\section{Introduction}

Out-of-pocket spending by households on healthcare constitutes a larger share of total health expenditure in India (72 percent in 2007) (WHO 2010a). Health insurance (hereafter HI) is often considered both desirable and affordable as access to insurance can in principle not only reduce the out-of-pocket expenditure of households but also diversify their financial risk, potentially raise income levels and can offer large welfare gains (WHO 1993; Townsend 1994; WHO 2000; Pauly, Zweifel et al. 2006; Alexander S. Preker 2009; WHO 2010b).

In India, people in the formal sector have been covered with several government sponsored HI schemes. In recent years, people 'below poverty line' (BPL) and other weaker sections are being covered with publicly funded HI schemes. But majority of the Indian population including the middle income groups do not come under the purview of any such schemes. Evidences show that healthcare expenditure has been pushing many of such households to BPL (Peters 2002). One of the options can be enrolling in voluntary HI schemes. Several insurance companies have been selling HI schemes to the general public since 1987 and the insurance market is growing, with the presence of more than 24 general and 23 non-general insurance companies as on 2010-11 (GoI 2011c). However, such voluntary HI 
schemes have covered only small portion of the population - around 3 per cent as on 2008-09 (GoI 2011c). Of these, majority are members of employee HI, which means that voluntary components of enrolment are even smaller.

The variety of factors that may affect enrolment can be classified as supply side and demand side factors. On the supply side are factors including availability of attractive HI products, ease of reimbursement, product support from insurance companies etc. Further, the problem of adverse selection- a situation of relatively more unhealthy people buy HI than healthy as people themselves know more about their health than insurers- in enrolment (Akerlof 1970; Rothschild and Stiglitz 1976) is considered as one of the potential reasons affecting the supply of HI.

On the demand side are factors that might underlie the ability and willingness to enrol. Some studies from developed countries found that income, education and health risks are major predictors of enrolment in voluntary HI (Cameron and Trivedi 1991; Propper 1993; Madden, Cheadle et al. 1995). Thus, one could argue that India is very conducive for higher level of HI enrolment. For instance, India has been experiencing higher economic growth with larger numbers of higher and middle income households along with increasing educational level (GoI 2011d) and higher out-of-pocket spending on healthcare due to double burdens of both communicable and non-communicable diseases (WHO 2010).

However, in developing countries, an often identified constraint in selling insurance is lack of understanding of insurance products by people and the differences in their cognitive ability to understand such products (McCord 2001; Cole, Gine et al. 2010). Further, several studies in the context of community-based HI schemes in developing countries including India showed that factors such as socioeconomic status, socio-cultural practices, institutional rigidities, trust over insurers, support from insurers, level of financial protection and distance to healthcare facility from insurance matter in enrolment in HI (Ahuja and Jütting 2004; Devadasan, Ranson et al. 2004; Acharya and Ranson 2005; Schneider 2005; De Allegri, Kouyaté et al. 2006; De Allegri, Sanon et al. 2006; Devadasan, Ranson et al. 2006; Nishant and Ramesh 2006; Basaza, Criel et al. 2007; Dror, Radermacher et al. 2007; Sinha, Ranson et al. 2007; Nguyen and Knowles 2010). However, to the best of our knowledge, there have been no significant research studies that examined the underlying reasons for such low levels of enrolment and the determinants of enrolment in voluntary HI schemes in India.

In these contexts, using both qualitative and qualitative research methods, this study explored the determinants of enrolment in voluntary HI in Kerala, India. More specifically, this study attempted to understand why only a few people enrol in voluntary HI while majority does not. In addition, this study examined the characteristics of enrolment in terms of income-related inequality and adverse selection problem.

\section{Data and Methods}

\subsection{Study Design}

This is a cross sectional study with a mixed method approach. It consists of qualitative and quantitative research methods. The qualitative research method was used to identify factors related to enrolment in HI and also used to develop conceptual and theoretical frame for further analysis. Subsequently, the significance of the determinants of enrolment in HI was estimated with quantitative study methods.

\subsection{Study Instruments}

The in-depth interview was used for qualitative study whereas the household survey for quantitative study and both were carried out by the author directly. The study site is the state of Kerala. The field study was conducted during a six month time period in 2007-08.

2.2.1 In-depth Interview: The in-depth interviews- sample size of 60- were conducted among the officials of insurance companies, insurance consultants, insured and uninsured people with semi-structured open-ended questionnaires. A total of 12 officials of insurance companies- 4 regional and 8 branch managers- were interviewed. The sample of officials of insurance companies belongs to the four public sector general insurance companies: National Insurance Company (NIC), United Insurance Company (UIC), New India Assurance Company (NIAC) and United India Insurance Company (UIIC). Further, in-depth discussion have been organised with 16 randomly selected insurance consultants (insurance consultants are commonly known as insurance agents). Moreover, 16 insured and 16 uninsured people were interviewed.

All the respondents were from the districts of Kasaragod (less developed region) and Trivandrum (developed region) in the state of Kerala, India. The in-depth interviews were conducted in the local language (except for regional managers) and back-translated to English. The transcription were finalised on the same day to avoid any information lapse, using handwritten notes. 
2.2.2 Household Survey: The survey was conducted among both insured and uninsured households, and the household heads were interviewed.

Sampling: We took a stratified random sample with equal numbers of insured (cases) $(n=200)$ and uninsured (controls) - a total 400 households. For a case-control study with anticipated probability of exposure (health insurance) among households of the surveyed area of 3\% and with $90 \%$ power, the sample size required is 192 cases and 192 controls. After adjusting the cases and controls for 10\% non-response and rounding-off, the required sample size is 220 insured and 220 uninsured, and finally the information was collected from 200 insured and 200 uninsured.

Selection of households: The households were selected from the districts of Kasaragod and Trivandrum of Kerala. The insured households are those having a 'Mediclaim Policy' (a voluntary HI scheme) for at least one member of the household with any of the four public sector insurance companies. The Mediclaim policies of these companies were selected as the sample HI scheme because HI in India is generally equated with Mediclaim policy. Moreover, Mediclaim policy has been in the market since 1987 and the rest of the HI schemes in the country follow the features of Mediclaim policies. Since the enrolees of HI schemes belong to both employees HI and general population in which the latter are more voluntary in nature, the sample of insured households was taken from the general population.

The sample of uninsured households did not have a Mediclaim policy, irrespective of their enrolment status with other forms of insurance such as life insurance, vehicle insurance etc. With the objective to understand why some people buy HI while others do not, the sample of the uninsured group was randomly selected from the neighbourhood of insured households.

Statistical analysis: Survey data were double-entered in to Microsoft Access database. The statistical analysis was performed with STATA 10.0 (StataCorp 2010). Both bivariate and multivariate analyses were used.

The logistic regression model was used to measure the association of various factors with enrolment in HI. The estimated odds ratio of each dependent variable is adjusted with the rest of the variables. The response variable $Y_{i}$ is a binary variable and defined as $\mathrm{y}=1$ if at least one household member has enrolled in HI, and $\mathrm{y}=0$ otherwise. The explanatory variables are income, education, health risk, and the variables related to awareness on insurance and role of insurance consultants.

Income is measured in terms of assets of the households and subsequently converted in to a composite index using the principal component analysis. For analysis, this income index has been categorised in to 3 groups, namely, low, middle and high income. Education is defined as the highest educational qualification in the household and is classified in to four categories: 'No formal education', 'Primary school', 'High/secondary school', and 'College/university education)'.

The health risk is the variable used to measure the presence of adverse selection in enrolment. Since health risk is a multidimensional phenomenon and is determined by many observable and non-observable factors, we reviewed several indicators of health risk. Subsequently, health risk is defined as 'whether any member in the household has had a bad health situation such as permanent health problems, recurring illness or chronic health situation in the past one year'.

In addition, we have defined four more variables as explanatory variables that were identified through in-depth interview: 1. basic awareness on insurance, 2. enrolment status with risk-insurance, 3. enrolment status with risk-plus-savings-insurance, and 4. insurance consultant. Of these, the first three variables were used to denote the awareness of people about insurance.

We defined the awareness on insurance after classifying the concept of awareness about insurance in to: i) basic awareness, and ii) in-depth awareness. The basic awareness on insurance is defined as 'whether or not the respondent heard about any HI products'. To the insured households, this question has been rephrased as 'whether or not heard about any HI products other than Mediclaim policy'. Further, the in-depth awareness (Note 1) is defined as i) enrolment status with risk-insurance (e.g. vehicle insurance, fire insurance, house insurance etc), and ii) enrolment status with risk-plus-savings-insurance (e.g. life insurance).

Finally, the variable 'insurance consultant' is included in the model to capture the role of insurance consultants in enrolment and is defined as 'whether or not any household member has been approached by insurance consultant to discuss HI'. 


\section{Results}

The tables (Table 1 and Table 2), generated from the household survey, show that people are not fully aware of the insurance market and the available products. Moreover, majority of those who bought a 'Mediclaim policy' were not aware of the other available HI schemes in the market at the time of buying the HI product, which means that they were not well-informed consumers.

Table 1. Basic awareness about insurance providers by insured and uninsured (\%)

\begin{tabular}{lll}
\hline Heard about: & $\begin{array}{l}\text { Insured } \\
(\mathbf{N = 2 0 0 )}\end{array}$ & $\begin{array}{l}\text { Uninsured } \\
(\mathbf{N}=\mathbf{2 0 0})\end{array}$ \\
\hline General insurance companies (any of) & 100 & 29.5 \\
Non-general insurance companies (any of) & 100 & 99 \\
General public sector insurance companies (any of) & 100 & 29.5 \\
General private sector insurance companies (any of) & 13 & 2.5 \\
Non-general public sector insurance companies (any of ) & 100 & 99 \\
Non-general private sector insurance companies (any of) & 12 & 2 \\
Motor vehicle insurance & 87 & 78 \\
Life insurance & 100 & 92 \\
\hline
\end{tabular}

Source: Household survey

Table 2. Awareness of various health insurance products by insured and uninsured (\%)

\begin{tabular}{lll}
\hline Heard about & $\begin{array}{l}\text { Insured } \\
(\mathbf{N = 2 0 0})\end{array}$ & $\begin{array}{l}\text { Uninsured } \\
(\mathbf{N}=\mathbf{2 0 0})\end{array}$ \\
\hline Health insurance by general insurance companies & 100 & 14 \\
1) Mediclaim policy & 15 & 2 \\
2) Jan Arogya policy & 7 & 4 \\
HI by non-general insurance companies & 2 & 1.5 \\
HI provided by community organizations & 11 & 8 \\
HI provided by hospitals & & \\
\hline
\end{tabular}

Source: Household survey

Table 4 shows the significance of the relevant variables in a multivariate framework using logistic regression model. The model further shows no association of 'basic awareness' with enrolment. However, the variables related to in-depth awareness shows a significant relationship with enrolment. That is, individuals enrolled in 'risk-insurance' as compared to those who have not enrolled in 'risk-insurance' have higher odds (odds ratio: 14.05 with $95 \%$ CI: 6.17 to 32.00) of enrolling in HI. Similarly, enrolment status with 'risk-plus-saving insurance' has statistically significant association with higher odds (odds ratio 5.46 with 95\% CI: 2.98 to 10.01) of enrolling in HI.

Table 4. Descriptive statistics and the adjusted odds ratio from logistic regression model

\begin{tabular}{|c|c|c|c|c|}
\hline & $\begin{array}{l}\text { Insured } \\
(\mathrm{N}=\mathbf{2 0 0})\end{array}$ & $\begin{array}{c}\text { Uninsured } \\
(\mathrm{N}=\mathbf{2 0 0})\end{array}$ & $\begin{array}{c}\text { Adjusted Odds Ratio } \\
\text { (95\% Confidence } \\
\text { Interval) } \\
\end{array}$ & P value \\
\hline \multicolumn{5}{|l|}{ Income } \\
\hline $\begin{array}{l}\text { Low income (reference } \\
\text { category) }\end{array}$ & $26.5 \%$ & $39.5 \%$ & 1.00 & \\
\hline Middle income & $34.5 \%$ & $32.5 \%$ & $\begin{array}{c}1.09 \\
(0.75 \text { to } 2.95)\end{array}$ & $\mathrm{P}=0.25$ \\
\hline High income & $39 \%$ & $28 \%$ & $\begin{array}{c}2.01 \\
(1.09 \text { to } 4.01)\end{array}$ & $\mathrm{P}=0.04$ \\
\hline \multicolumn{5}{|l|}{ Education } \\
\hline $\begin{array}{l}\text { No formal education } \\
\text { (reference category) }\end{array}$ & $2 \%$ & $2 \%$ & 1.00 & \\
\hline Primary school & $33 \%$ & $31 \%$ & $\begin{array}{c}2.20 \\
(0.37 \text { to } 12.88)\end{array}$ & $\mathrm{P}=0.38$ \\
\hline High/secondary school & $42.5 \%$ & $45 \%$ & $\begin{array}{c}1.90 \\
(0.33 \text { to } 10.97)\end{array}$ & $\mathrm{P}=0.46$ \\
\hline College/university & $22.5 \%$ & $22 \%$ & 2.09 & $\mathrm{P}=0.42$ \\
\hline
\end{tabular}


education
Health risk

Low risk (reference

category)

High risk

\section{Basic-awareness}

Not heard about HI

(reference category)

Heard

\section{Enrolment status with \\ Risk-insurance}

Not enrolled (reference

category)

Enrolled

\section{Enrolment status with \\ Risk-plus-saving-insurance}

Not enrolled (reference

category)

Enrolled

\section{Insurance consultant}

Was Not approached

(reference category)

Approached

\section{International Journal of Financial Research

Interntiona Journal of Financial Research

(0.34 to 12.58)

$80 \%$
$20 \%$

$78 \%$

$22 \%$

$45 \%$

$55 \%$

$32 \%$

$68 \%$

$24 \%$

$76 \%$
$78 \%$

$22 \%$

$86 \%$

$14 \%$

$92 \%$

$8 \%$

$72 \%$

$28 \%$

$93 \%$

$7 \%$
1.00

0.84

(0.46 to 1.66$)$

1.00

1.73

(0.82 to 3.66$)$

1.00

14.05

(6.17 to 32.00 )

1.00

5.46

(2.98 to 10.01 )

1.00

31.07

(17.19 to 87.94)
$\mathrm{P}=0.72$

$\mathrm{P}=0.14$

Further, the in-depth interview (see Box 1 for summary of findings from in-depth interview) has revealed that the socio-cultural and institutional rigidities such as difficulty to deal with insurers, lack of knowledge about rules and modalities of insurance schemes, poor trust over insurance companies on reimbursement of claims and absence of attractive HI products (Note 2) make the formal risk pooling less attractive. Thus, instead of dealing with the formal insurance system, people prefer to rely on own savings or borrowings from friends, relatives etc. as informal insurance system. Moreover, given the low level of income to meet so many basic necessities of life such as food, education, shelter etc., people do not consider buying HI as a viable option. Since buying HI means switching a part of their savings portfolio to pay a premium, people find it more worth to put money into general savings that are flexible, to be directed as per need or emergencies, including healthcare instead of paying premiums in ex-ante for 'uncertain' health events.

Box 1. Factors related to enrolment in HI

\begin{tabular}{|c|c|c|}
\hline & Negative factors & Positive factors \\
\hline & $\begin{array}{l}\text { i. low level of awareness of people on } \\
\text { insurance system }\end{array}$ & $\begin{array}{l}\text { i. Financial protection } \\
\text { ii. To experiment with HI }\end{array}$ \\
\hline Demand side & $\begin{array}{l}\text { ii. Attitudes of people towards formal risk } \\
\text { pooling }\end{array}$ & iii. Income tax benefit \\
\hline Supply side & $\begin{array}{l}\text { iii. Absence of attractive HI products } \\
\text { i. Low motivation for insurance companies } \\
\text { ii. Difficulty in monitoring the healthcare } \\
\text { provision } \\
\text { iii. Less incentive for insurance consultants }\end{array}$ & $\begin{array}{l}\text { i. To benefit from the growing healthcare } \\
\text { market } \\
\text { ii. Government clause of rural and social } \\
\text { insurance quota }\end{array}$ \\
\hline
\end{tabular}

Source: In-depth Interview

The estimates from the logistic regression (Table 4) further show that the economic status of the households showed statistically significant association with enrolment in $\mathrm{HI}$, with individuals from the richest households having an odds ratio for enrolment 2.01 (95\% CI: 1.09 to 4.01) compared to those from the poorest households. However, there is no 
statistically significant association of education with enrolment. Furthermore, no association of health risk with enrolment is observed, which means no evidence of adverse selection in enrolment in HI.

The logistic regression model also shows that statistically significant association of 'insurance consultant' with enrolment in HI (odds ratio 31.07 with $95 \%$ CI: 17.19 to 87.94). This finding can be further substantiated with findings from Table 3, which shows that insurance consultants are main source of information about 'Mediclaim policy' as compared to other sources such as media, offices of insurance companies, friends and workplace.

Table 3. Main source of information on mediclaim policy (\%)

\begin{tabular}{lll}
\hline Main source of information & Insured $(\mathbf{N}=\mathbf{2 0 0})$ & Uninsured $(\mathbf{N}=\mathbf{2 0 0})$ \\
\hline Insurance Consultants & 76 & 7 \\
Media & 2 & 2 \\
Friends, workplace etc. & 12 & 4 \\
Offices of insurance companies & 10 & 2 \\
Total & 100 & 14 \\
\hline
\end{tabular}

Source: Household survey

It was found during the in-depth interview that insurance consultants prefer to sell more life insurance schemes than HI schemes. They often face a trade-off in selling general (e.g. HI) and non-general insurance (e.g. life insurance) different types of insurance policies that have various rates of income return. As the rate of return of income for insurance consultants from the sale of insurance schemes is a positive function of premium, the return of income from the sale of $\mathrm{HI}$ is less than of life insurance, per unit of business. This is because HI schemes i) charge lower premium compared to life insurance products for a given insured amount as the premium of the former has 'risk pooling' components alone, and ii) have a term of only one year. On the other hand, the life insurance schemes have both 'risk pooling and savings' components and are long term schemes, and therefore have higher premiums.

There also exist differences in the time and efforts (costs) required for selling HI and life insurance. Generally, it takes a lot more effort and time to sell an HI scheme than a life insurance scheme. It is relatively easier for insurance consultants to convince a prospective client of the importance of buying life insurance as it has both 'saving and risk pooling' components. On the other hand, the sale of HI schemes takes more time and effort, and needs 'after sales services' to clients such as annual renewal, assistance in claim reimbursement etc.

The in-depth interview with officials of insurance companies revealed that they are reluctant to follow aggressive marketing strategies for selling HI schemes to general public because $\mathrm{HI}$ is a loss making business. The HI business constitutes meagre components of the entire insurance portfolio. As compared to other forms of insurance, the HI requires more administrative cost and often becomes a loss making entity due to adverse selection and utilisation-related moral hazard problems. In order to minimise adverse selection problem and administrative cost, they focus on the sale of employee's group HI schemes rather to the general public.

Contracting private healthcare provider and monitoring healthcare utilisation is another major concern for insurance companies, as revealed by the insurance officials. Since Indian healthcare market is highly unregulated one with no standardised treatment protocol, no benchmark either in fixation of prices or in provision of healthcare services, it is difficult to monitor healthcare services delivery. However, the growing size of Indian healthcare market is a motivating factor to expand the supply of HI. Moreover, the official clause of 5 percent rural/social quota fixed by Government of India to increase insurance penetration in backward areas also motivates them to increase supply of HI.

\section{Discussion}

This study attempted to explore the factors affecting the enrolment in HI. We found that low level of awareness of people about insurance and the significant role of insurance consultants play a major role in addition to income, education and health risk in determining enrolment in HI. The study also found that the insurance consultants have significant roles in enrolment because they are being the major source of information on HI.

Further, we have found through the household survey that there is income-related inequality but no adverse selection in enrolment. During the in-depth interview, we observed the implication of incentives available in the market for insurance consultants in these outcomes. In general, insurance consultants prefer to sell HI to the high income households, therefore increase inequality in enrolment, because rich would be more likely to not only to buy HI but also to buy higher amount of HI than low-income households, which would result in high income return per unit of business (Note 3). 
Further, there is possibility that insurance consultants attempt to reduce the level of adverse selection. Insurance consultants can select their clients from the socio-economic and geographical locations they are more familiar with, and hence more probable to know them individually including their health conditions. As HI in India is generally sold in 'good faith' in the form of self declaration of health status by prospective clients without any medical tests; therefore, asymmetric information on health risk becomes significant. In this context, we can expect that insurance consultants minimise adverse selection by selling HI mainly to low-risk people because insurance companies would appreciate their consultants selling insurance schemes to low-risk people as this would reduce insurance claims. However, it is difficult to make a final conclusion on their role in minimising adverse selection. There can be some instances where insurance consultants also promote adverse selection by selling $\mathrm{HI}$ to those who need healthcare in the immediate future due to their personal proximity with their clients.

In order to enhance the enrolment rate as well as reduce the income related inequality in enrolment, the Insurance Regulatory and Development Authority (IRDA) should make it obligatory for insurance companies to provide sufficient incentives to insurance consultants for selling HI. The term of HI should be converted to long-term one (say for example 15 years as like life insurance) instead of the current practice of annual renewal. In addition, feasibility of selling HI through non-profit entities (e.g. self-help groups, Panchayatraj institutions) and the option of merging with 'community-based HI' should be explored.

As we found that the level of awareness has significant association with enrolment in HI, people should be given an opportunity to experience insurance so that they understand what insurance is all about. In this regard, low and middle-income households should be given free or subsidised HI to familiarise them with HI; after a point, the subsidy can gradually be withdrawn. The recent initiatives of both central and various state governments on introducing fully premium-subsidised social $\mathrm{HI}$ is a welcome move.

Strengthening the healthcare market with developing guidelines for pricing and delivery of healthcare, and suitable provider payment mechanism is another precondition for not only increasing the HI penetration but also to ensure the $\mathrm{HI}$ enrolment delivers the impact on the insured. For instance, evidences from the Chinese health insurance program showed that the program has not yielded the desired impact but led to higher out-of-pocket expenditure and an overall cost escalation in the healthcare system; the possible reason might be pitfalls in contacting private healthcare providers (Wagstaff and Lindelow 2008).

Strengths, limitations, and scope for future research: This study contributes to the current knowledge on why only a few people buy health in HI in India, using mixed method approach. The findings of this study have implications at the national level and in other developing countries with similar socio-economic setting.

However, this study has some limitations. One is related to the sampling frame of the household survey, which has resulted in the non-generalisability of some of the findings. For instance, in contrast to evidence from the developed countries context, we found from the household survey that income is moderately associated with enrolment in HI. And, education has no association with the enrolment. Both these findings need careful examination.

The data from the insurance companies showed that $98 \%$ of the insured households were from urban and semi-urban locations, therefore our sample of insured were from urban population only. Moreover, our sampling strategy resulted in taking not only $98 \%$ sample of insured households but also equal number of uninsured households from the urban locations and thus comparing the urban with urban. It is a well known fact that the urban population has higher income than their rural counterparts. This is true in the case of education too. Therefore, if we make a comparison of the income and education of the urban population with rural population would reveal that both income and education will be highly significantly and positively affect the enrolment.

Secondly, there can be several state-specific and different socio-cultural factors affecting the enrolment. However, the current study has taken only the state of Kerala as study site due to resource constraint. Thirdly, as we interviewed the household heads, $91 \%$ of our respondents were happened to be male and of people of age of above 40 years.

Therefore, to have more robust results and wider implications, the determinants of enrolments should be further investigated using more nationally representative sampling framework with different population groups consisting of male-female, young-older, different religions, rural- urban populations. In addition, further in-depth research related to renewal of HI also required. Moreover, we need to generate evidences on whether voluntary HI schemes yielded desired impacts. There are some studies in India, which used rigorous impact evaluation techniques, showed that community-based HI schemes enhanced access to healthcare and reduce financial burden of households due to 
healthcare (Devadasan, Criel et al. 2007; Aggarwal 2010; Devadasan, Criel et al. 2010); similar evaluation needs to be performed on voluntary HI too.

\section{References}

Acharya, A., \& M. K. Ranson. (2005). Health care financing for the poor: community-based health insurance schemes in Gujarat. Economic and Political Weekly, 4141-4150.

Aggarwal, A. (2010). Impact evaluation of India's 'Yeshasvini'community based health insurance programme. Health Economics, 19 (S1), 5-35. http://dx.doi.org/10.1002/hec.1605

Ahuja, R., \& J. Jütting (2004). Are the poor too poor to demand health insurance? Journal of Microfinance, 6(1), $1-21$.

Akerlof, G. A. (1970). The market for" lemons": Quality uncertainty and the market mechanism. The quarterly journal of economics, 488-500. http://dx.doi.org/10.2307/1879431

Alexander S. Preker, P. Z., Onno, \& P. Schellekens. (Eds.) (2009). Global Marketplace for Private Health Insurance: Strength in Numbers. World Bank.

Basaza, R., B. Criel, et al. (2007). Low enrolment in Ugandan Community Health Insurance Schemes: underlying causes and policy implications. BMC health services research, 7(1), 105. http://dx.doi.org/10.1186/1472-6963-7-105

Cameron, A. C., \& P. K. Trivedi. (1991). The role of income and health risk in the choice of health insurance: Evidence from Australia. Journal of Public Economics, 45(1), 1-28. http://dx.doi.org/10.1016/0047-2727(91)90045-4

Cole, S., X. Gine, et al. (2010). Barriers to household risk management: evidence from India. World Bank.

De Allegri, M., B. Kouyaté, et al. (2006). Understanding enrolment in community health insurance in sub-Saharan Africa: a population-based case-control study in rural Burkina Faso. Bulletin of the World Health Organization, 84(11), 852-858.

De Allegri, M., M. Sanon, et al. (2006). “To enrol or not to enrol?”: A qualitative investigation of demand for health insurance in rural West Africa. Social Science \& Medicine, 62(6), 1520-1527. http://dx.doi.org/10.1016/j.socscimed.2005.07.036

Devadasan, N., B. Criel, et al. (2007). Indian community health insurance schemes provide partial protection against catastrophic health expenditure. BMC Health Services Research, 7, 43. http://dx.doi.org/10.1186/1472-6963-7-43

Devadasan, N., B. Criel, et al. (2010). Community health insurance in Gudalur, India, increases access to hospital care. Health Policy \& Planning, 25(2), 145-154. http://dx.doi.org/10.1093/heapol/czp044

Devadasan, N., K. Ranson, et al. (2004). Community health insurance in India: an overview. Economic and Political Weekly, 39(28), 3179-3183.

Devadasan, N., K. Ranson, et al. (2006). The landscape of community health insurance in India: An overview based on 10 case studies. Health Policy, 78(2), 224-234. http://dx.doi.org/10.1016/j.healthpol.2005.10.005

Dror, D. M., R. Radermacher, et al. (2007). Willingness to pay for health insurance among rural and poor persons: field evidence from seven micro health insurance units in India. Health Policy, 82(1), 12-27. http://dx.doi.org/10.1016/j.healthpol.2006.07.011

GoI. (2011c). Insurance Regulatory and Development Authority, Government of India.

GoI. (2011d). Census of India.

Madden, C. W., A. Cheadle, et al. (1995). Voluntary public health insurance for low-income families: the decision to enroll. Journal of Health Politics, Policy and Law, 20(4), 955. http://dx.doi.org/10.1215/03616878-20-4-955

McCord, M. J. (2001). Health care microinsurance-case studies from Uganda, Tanzania, India and Cambodia. Small Enterprise Development ,12(1), 25-38. http://dx.doi.org/10.3362/0957-1329.2001.006

Nguyen, H., \& J. Knowles. (2010). Demand for voluntary health insurance in developing countries: The case of Vietnam's school-age children and adolescent student health insurance program. Social Science \& Medicine. http://dx.doi.org/10.1016/j.socscimed.2010.09.033 
Nishant, J., \& B. Ramesh. (2006). Factoring affecting the demand for health insurance in a micro insurance scheme. IIMA Working Papers.

Pauly, M. V., P. Zweifel, et al. (2006). Private health insurance in developing countries. Health Affairs, 25(2), 369. http://dx.doi.org/10.1377/hlthaff.25.2.369

Peters, D. H. (2002). Better health systems for India's poor: findings, analysis, and options. World Bank Publications. http://dx.doi.org/10.1596/0-8213-5029-3

Propper, C. (1993). Constrained choice sets in the UK demand for private medical insurance. Journal of Public Economics, 51(3), 287-307. http://dx.doi.org/10.1016/0047-2727(93)90067-4

Rothschild, M., \& J. Stiglitz (1976). Equilibrium in competitive insurance markets: An essay on the economics of imperfect information. The quarterly journal of economics, 90(4), 629-649. http://dx.doi.org/10.2307/1885326

Schneider, P. (2005). Trust in micro-health insurance: an exploratory study in Rwanda. Social Science \& Medicine, 61(7), 1430-1438. http://dx.doi.org/10.1016/j.socscimed.2004.11.074

Sinha, T., M. K. Ranson, et al. (2007). Why have the members gone? Explanations for dropout from a community-based insurance scheme. Journal of International Development, 19(5), 653-665. http://dx.doi.org/10.1002/jid.1346

StataCorp. (2010). Intercooled Stata 10 for windows. College Station TX, StataCorporation.

Townsend, R. M. (1994). Risk and insurance in village India. Econometrica, 62(3). 539-591. http://dx.doi.org/10.2307/2951659

Wagstaff, A., \& M. Lindelow. (2008). Can insurance increase financial risk?: The curious case of health insurance in China. Journal of health economics, 27(4), 990-1005. http://dx.doi.org/10.1016/j.jhealeco.2008.02.002

WHO. (1993). World development report 1993: investing in health. World Health Organisation. Oxford University Press.

WHO. (2000). The world health report 2000: Health systems: improving performance. World Health Organization, Geneva.

WHO. (2010). World Health Statistics 2010 Geneva. World Health Organisation.

WHO. (2010a). World Health Statistics Geneva. World Health Organisation, Geneva.

WHO. (2010b). The world health report - Health systems financing: the path to universal coverage. World Health Organisation, Geneva.

\section{Notes}

Note 1. As the HI products are featured with risk pooling component alone, we hypothesise that the enrolment status with general insurance (risk-insurance) can have in-depth awareness and thus have a positive impact on buying $\mathrm{HI}$ as compared to those enrolled with non-general insurance (risk-plus-savings-insurance) products.

Note 2. The existing HI products in the market cover only in-patient expenses and exclude out-patient expenses and several other diseases including pre-existing diseases.

Note 3. Moreover, insurance consultants prefer to sell $\mathrm{HI}$ to those who have higher in-depth awareness as a complementary product to life and other forms of insurance because this may reduce average cost of selling HI. Less time and efforts are required to sell HI schemes to those familiar with insurance system and would have the understanding of the risk pooling nature of insurance and, hence, do not expect the money back if they do not fall sick. 